\title{
Can fixation instability improve text perception during eccentric fixation in patients with central scotomas?
}

\author{
A Déruaz, M Matter, A R Whatham, M Goldschmidt, F Duret, M Issenhuth, A B Safran
}

Br J Ophthalmol 2004;88:461-463. doi: 10.1136/bjo.2003.025601

\begin{abstract}
Background: Oculomotor behaviour was investigated in 14 patients with central scotomas from age related macular degeneration (AMD) or Stargardt's disease. A scanning laser ophthalmoscope (SLO) was used to project letters and words onto the retina and to assess fixation behaviour. Five patients reported while deciphering letters that they needed to "move their eye" to prevent the image from vanishing. The observation of the SLO fundus images revealed that the gradual disappearance of the stimulus did not result from a transient projection of the word in the lesion. This prompted the authors to investigate, in an experimental setting, whether purposeful changes in fixation position could improve the perception of an eccentrically fixated text stimulus.

Methods: Twenty normal subjects were asked to alternate fixation, every three to four seconds, between two vertically aligned dots, spaced $10^{\circ}$ apart, and to report any changes in the perception of a laterally located letter, $1.5^{\circ}$ in height, $7^{\circ}$ apart and equidistant between the two fixation spots.

Results: Nineteen subjects reported a transient refreshment of the letter image immediately after the realisation of a saccade. Improved perception lasted approximately a second. With persistent fixation, they noted a rapid fading effect that reduced letter recognition.

Conclusion: These observations suggest that ocular instability during eccentric viewing can have a functional advantage, probably related to counteracting Troxler's phenomenon. In addition to alternating between PRLs, it appears that saccades related to fixation instability might be valuable and improve text perception in individuals with a central scotoma and eccentric fixation. This possibility should be taken into consideration when conducting visual rehabilitation procedures.
\end{abstract}

S ince it was first observed that patients with central scotomas can develop an eccentric preferred retinal area to fixate targets, ${ }^{1}$ the concept of preferred retinal locus (PRL) has been widely recognised. In a large study on such patients, it was found that $84 \%$ of affected eyes showed an established eccentric PRL. ${ }^{2}$ This PRL is used to fixate targets and to read isolated words or paragraphed text. ${ }^{3-9}$ Recent investigations have shown that some affected individuals develop multiple PRL, where each PRL can be used predictably according to various parameters such as background illumination ${ }^{10}$ or interchangeably during a reading task. ${ }^{11-13}$ In the latter case, PRLs have been described to have specific complementary functions. Some PRLs allowed patients a fine letter resolution, while others a global viewing of a segment of text. ${ }^{11}{ }^{13}$ We also reported that patients can become conscious of the position of their different PRLs and their respective functions after about 20 minutes of guided reflection during eccentric viewing of words, and were finally able to voluntary switch between them. ${ }^{11}{ }^{12}$ It is probable that patients, who alternate between two or more PRLs, are able to switch their focus of attention as they change their fixation point.

During an ongoing investigation of reading strategies in subjects with bilateral central scotoma using scanning laser ophthalmoscopy (SLO) (Rodenstock, Munich, Germany), we observed a particular oculomotor behaviour in five out of 14 consecutively examined patients. While attempting to decipher a word, they performed rapid eye movements back and forth between two specific retinal areas. These were either two previously identified PRLs for reading or included one of them combined with another area which seemed to be specific to the observed fixation related eye movements (fig 1). To identify whether there was a perceptual based purpose to these movements we questioned the five patients showing the occurrence of such oculomotor behaviour during the word deciphering process. The patients reported that these eye movements seemed to "refresh" the image of the word, or to "flash" it. Their realisation appeared then to facilitate the reading process by counteracting the stimulus's disappearance. We finally asked the patients to try to stop moving their eyes, as much as possible, during persistent fixation of the word and to observe what happened. In the latter condition, they reported a quick fading of the stimulus. The observation of the SLO fundus images revealed that this disappearance was not the result of a projection of the word inside the borders of the scotoma (personal, unpublished data). The purpose of the present study was to further define the role of these fixation related eye movements by conducting a simulation of the phenomenon on subjects with normal vision.

\section{METHODS}

Twenty normal subjects (mean age 42 years, range 31-59), with normal best corrected visual acuity and no evidence of ocular pathology, were included in the study. The subjects were positioned in front and $1 \mathrm{~m}$ distant from a white board. We presented to them two vertically aligned fixation spots, spaced $10^{\circ}$ apart, and an eccentrically located letter (the letter " $\mathrm{A}^{\prime \prime}$ ). The letter was positioned $7^{\circ}$ to the left of and equidistant between the two dots. Its height was $1.5^{\circ}$ (see fig 2). This experimental setting reproduced the average size of the lesion retinal eccentricities, as well as the size of the letter, observed in the patients who reported the need to move their eye to counteract the stimulus's disappearance. The subjects were asked to alternately fixate each dot, in monocular viewing, during approximately four seconds and to describe any changes in their perception of the eccentric letter during the procedure.

\section{RESULTS}

Nineteen out of the 20 normal subjects reported that they best recognised the eccentric letter during approximately the first second of the new fixation period. Later, while 

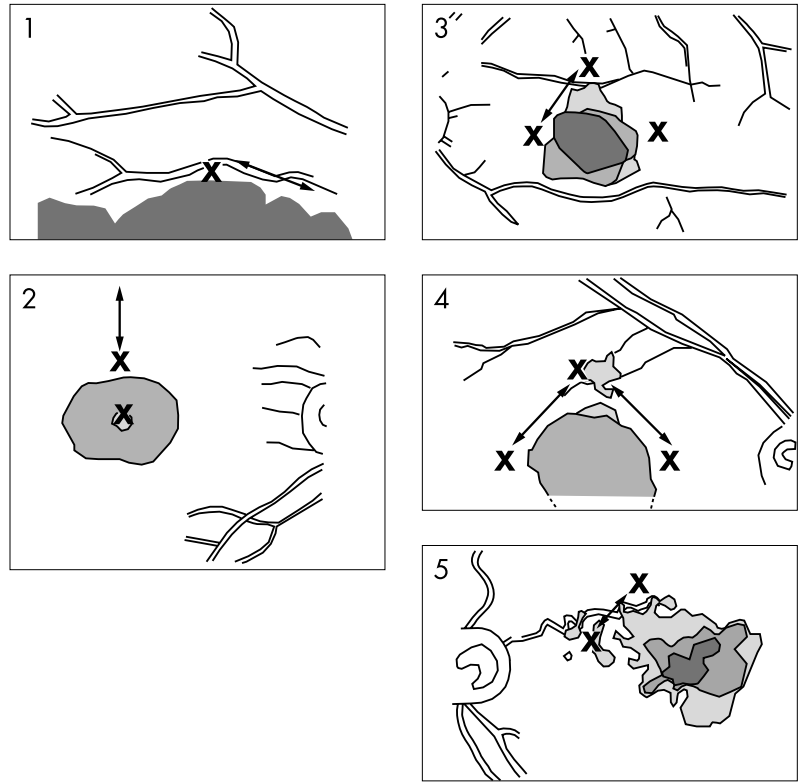

Figure 1 Scotoma location in the five patients who reported the need to perform fixation related eye movements. The $X s$ indicate the position of the PRL previously identified during the reading task and the arrows the direction of the fixation related eye movements observed. For patients 1 and 2 the fixation related eye movements were observed to occur from the PRL to an area not included in the PRL identified during reading. For patients 3,4 , and 5 these movements were performed between two PRL areas. Illustrations represent the fundus as seen through the SLO. As a result, the image is vertically inverted relative to the projection of the scotoma in visual space.

maintaining fixation for at least two to three seconds, a fading of the image occurred. Thus, movements between the fixation spots allowed a new fixation period with a revived perception of the image. The remaining subject reported that he best perceived the presented letter slightly before getting to the new fixation position.

\section{DISCUSSION}

The observations of normal subjects corroborated the phenomenon previously observed in patients with central scotomas. Nineteen out of 20 subjects reported that the change in fixation position induced a revival of the letter image counteracting the fading effect.

When describing rehabilitation procedures for patients with a central scotoma by improving the stability of fixation, it has been suggested that achieving eccentric fixation in a discrete and stable area is valuable. ${ }^{214-16}$ From the results reported here, fixation related eye movements seem, at least in some affected individuals, to underlie a strategy used to compensate for a perceptual fading phenomenon occurring while attempting to decipher isolated letters or words. The above reported perceptual phenomenon bears similarities with that known as Troxler's effect, which refers to the rapid fading of an eccentrically fixated target. ${ }^{17}$ Troxler's effect was first described as the gradual perceptual disappearance of an image stabilised at an eccentric retinal location after several seconds, and its instantaneous reappearance if the fixation position changes. It was later observed that this phenomenon occurred foveally too, although weaker and with a longer time course. ${ }^{18}$ Recently it has been postulated that the effect is mediated at a post-receptoral (neuronal) level, rather than occurring as a direct result of the bleaching of photoreceptors at the stimulus position, ${ }^{19-23}$ and might be related to the filling in phenomenon. ${ }^{24} 25$

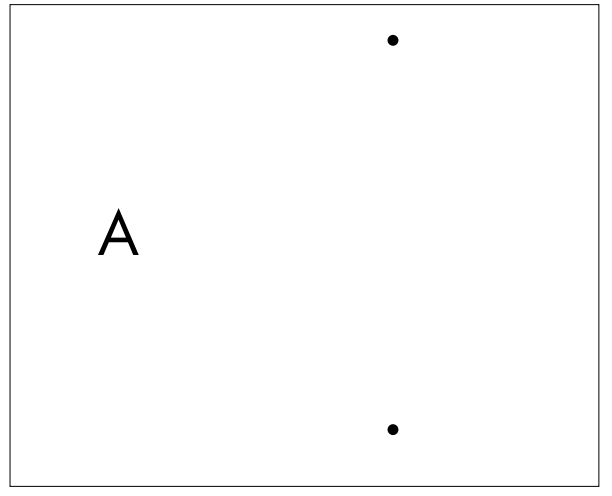

Figure 2 Experimental set up used to simulate the effect of eye movements on letter perception during eccentric fixation. The subjects were asked to look alternately at the two dots and, while making these movements, to report any perceptual changes they had of the eccentric letter. The phenomenon described can be experienced by the reader by shifting fixation from one dot to the other while viewing the figure at a distance of $20 \mathrm{~cm}$.

During physiological fixation, eye movements imperceptible to the subject constantly occur. They consist of slow small angle drifts (amplitude of approximately 2.5 minarc and frequency of $2-5 \mathrm{~Hz}$ ) interspersed with microsaccades (amplitude of less than 10 minarc, very variable frequency) and tremor (amplitude of less than 1 minarc and frequency of $30-80 \mathrm{~Hz}){ }^{26-28}$ The significance of each of these movements during the fixation process is controversial. It has been postulated that their occurrence counteracts the fading of the image stabilised on the retina ${ }^{29}$ but it is not clear whether the microsaccades $^{30}$ or the drifts ${ }^{31}$ primarily prevent this phenomenon. The nature and frequency of eye movements during foveal fixation appear to depend on the features of projected targets. ${ }^{30}$ Each of the three kinds of movements, acting separately, is sufficient to maintain tolerably good vision of high contrast targets with sharp boundaries. ${ }^{32}$ To fixate a luminance defined target with high contrast borders, ocular drifts and tremor movements, only acting together, can maintain a good level of visual perception. ${ }^{30}{ }^{32}$ Lastly, for targets of low contrast or with poorly defined boundaries, all three types of movements are required for a stable visual perception. $^{32}$

The eccentric fixation instability described here differs, however, from those observed during foveal fixation. Firstly, the resulting eye movements are of larger amplitude and, secondly, the patients are conscious or can be made aware of their presence. The difference observed in the amplitude of fixation related eye movements between foveal and peripheral fixation could be related either to the increased size of the receptive fields in the periphery of the visual space and/or to a greater difficulty to control eye movements centred on a peripheral retinal area. ${ }^{243-35}$ It has been shown that, following the development of a central scotoma, oculomotor behaviour readapts and refocuses progressively around the PRL(s). During this process, the number of refixation eye movements or inappropriate reflex movements onto the nonfunctioning fovea, the previous centre of the occulomotor system, decrease. ${ }^{35}$

It is generally accepted that to be efficient a PRL should cover a retinal area as restricted as possible. ${ }^{9}$ As a result, it has been emphasised that low vision patients might be trained to reduce the size of this area. ${ }^{214} 16$ Based on the observations reported here it appears appropriate to reconsider whether or not it should be a goal in the rehabilitative training of people with a central scotoma to markedly stabilise their gaze. The need for purposeful fixation related eye movements could 
explain why, in some circumstances, a PRL should remain relatively large and forceful stabilisation of fixation could be deleterious. Rehabilitation training should be conducted on an individual basis in this regard. It also needs to be considered that a quantitative evaluation of fixation stability may depend upon the instrument used and on the evaluation conditions. Crossland and Rubin, for example, recently observed that the area of fixation was smaller, so the fixation was more stable, when using an SLO as opposed to an eye tracking system (SensoMotoric Instruments GmbH, Teltow/ Berlin, Germany) principally because the subject's head is restrained with a chin and forehead rest in the former instrument. ${ }^{36}$

So far in our investigations we have based our determination of the existence of distinct PRLs on the repeated observation of non-overlapping retinal areas used to fixate a visual target and to decipher a word. ${ }^{13}$ The areas identified during the fixation related eye movements in patients were either two previously identified PRLs used during the reading task, or included such a PRL combined with another area seemingly specific to the observed phenomenon (fig 1). This involves an update of our PRL definition with the possible task dependent use of different PRLs. Regarding this, the necessity of more precise names for functionally defined PRLs, such as fixation PRL or reading PRL, may come into existence.

The phenomenon described in the present study, occurring during the reading process in patients with eccentric fixation, might presumably be more complex than the simple visual task investigated here in normal subjects. However our experimental setting allowed a simplified model of the observed phenomenon to demonstrate the occurrence of Troxler's effect and the ability to counteract it by eye movements. This method of enhancing the ability to perceive and read a text stimulus may be equally applicable to the reading of an isolated letter or word, as well as the reading of a text passage. More investigations need to be done to better test the Troxler based hypothesis proposed here, in a quantitative experiment design.

Overall it appears that, in patients with central scotomas, apparent fixation instability is composed of different types of eye movements, including saccades performed to change the fixation point, saccades shifting the image from the nonfunctioning fovea to the new eccentric PRL, ${ }^{35}$ saccades used to switch between PRLs ${ }^{10-13}$ and fixation related eye movements described here apparently intended to counteract the fading process. Other movements of unknown function might also occur.

\section{ACKNOWLEDGEMENTS}

This investigation was supported by the Pro Visu Foundation and the Association pour le Bien des Aveugles, Geneva, Switzerland.

\section{Authors' affiliations \\ A Déruaz, M Matter, A R Whatham, M Goldschmidt, M Issenhuth, \\ A B Safran, Neuro-ophthalmology Unit, Ophthalmology Clinic, Department of Clinical Neurosciences and Dermatology, Geneva University Hospitals \\ F Duret, Department of Physiology and Pharmacology, Catholic University of Louvain, Louvain, Belgium}

Correspondence to: Anouk Déruaz, Neuro-ophthalmology Unit, Ophthalmology Clinic, Department of Clinical Neurosciences and Dermatology, Geneva University Hospitals, 22 Alcide Jentzer, 1211 Geneva 14, Switzerland; anouk.deruaz@hcuge.ch

Accepted for publication 13 August 2003

\section{REFERENCES}

1 Von Noorden GK, Mackensen G. Phenomenology of eccentric fixation. Invest Ophthalmol Vis Sci 1962;29:268-78.

2 Fletcher DC, Schuchard RA. Preferred retinal loci relationship to macular scotoma in a low-vision population. Ophthalmology 1997;104:632-8.

3 Cummings RW, Whittaker SG, Watson GR, et al. Scanning characters and reading with a central scotoma. Am J Optom Physiol Optics 1985;62:833-43.

4 Timberlake GT, Mainster WA, Peli E, et al. Reading with a macular scotoma. I. Retinal location of scotoma and fixation area. Invest Ophthalmol Vis Sci 1986;27: 1137-47.

5 Timberlake GT, Peli E, Essock EA, et al. Reading with a macular scotoma. II. Retinal locus for scanning text. Invest Ophthalmol Vis Sci 1987;28:1268-74.

6 Whittaker SG, Budd J, Cummings RW. Eccentric fixation with macular scotoma. Invest Ophthalmol Vis Sci 1988;29:268-78.

7 White JM, Bedell HE. The occulomotor reference in humans with bilateral macular disease. Invest Ophthalmol Vis Sci 1990;31:1149-61.

8 Guez J-E, Le Gargasson J-F, Rigaudière F, et al. Is there a systematic location for the pseudo-fovea in patients with central scotoma? Vision Res 1993;33:1271-9.

9 Schuchard RA, Fletcher DC. Preferred retinal locus, a review with application in low vision rehabilitation. Ophthalmol Clin North Am 1994;7:243-56.

10 Lei H, Schuchard RA. Using two preferred retinal loci for different lighting conditions in patients with central scotomas. Invest Ophthalmol Vis Sci 1997;38:1812-18.

11 Duret $F$, Issenhuth $M$, Safran $A B$. Combined use of several preferred retinal loci in patients with macular disorders when reading single words. Vision Res 1999;39:873-9.

12 Safran $A B$, Duret $F$, Issenhuth $M$, et al. Full text reading with a central scotoma: pseudo-regression and pseudo line losses. $\mathrm{Br} J$ Ophthalmol 1999;83:1341-7.

13 Déruaz A, Whatham AR, Mermoud C, et al. Reading with multiple preferred retinal loci: implications for training a more efficient reading strategy. Vision Res 2002;42:2947-57

14 Schuchard RA, Raash TW. Retinal locus for fixation: pericentral fixation targets. Clin Vision Sci 1992;7:511-20.

15 Trauzettel-Klosinski S, Tornow RP. Fixation behavior and reading ability in macular scotoma, assessed by Tuebingen manual perimetry and scanning laser ophthalmoscopy. Neuro-Ophthalmol 1996;16:241-53.

16 Nilsson UL, Frennesson C, Nilsson SEG. Location and stability of a newly esthablished eccentric retinal locus suitable for reading, achieved through training of patient with a dense central scotoma. Optom Vis $\mathrm{Sci}$ 1998;75:873-8.

17 Troxler D, Himlyk Schmidt A, eds. Uber das Verschwinden gegebener Geganstande innerhalb unseres Gesichtskreise. Ophthalmologie Bibliothek, Jena: Springer, 1804:431-573.

18 Clarke FJJ. Rapid light-adaptation of localized areas of the extra-foveal retina. Optica Acta 1957;4:69-77.

19 Cornwall MC, Fein A, MacNichol EF. Spatial localization of bleaching adaptation in isolated vertebrate rod photoreceptors. Proc Natl Acad Sci U S A 1983:80:2785-8.

20 Mainster MA, White TJ, Stevens CC. Mathematical analysis of rhodopsin kinetics. Vision Res 1971;11:435-47.

21 Fain GL, Matthews HR, Cornwall MC, et al. Adaptation in vertebrate photoreceptors. Physiol Rev 2001;81:117-51.

22 Ripps H, Weale RA. Rhodopsin regeneration in man. Nature 1969;222:775-7.

23 Hart WM. Visual adaptation. In: Hart WM, ed. Adler's physiology of the eye: clinical application, 8th edition. St Louis, MO: The CV Mosby Company, 1987:395.

24 Safran $A B$, Landis $T$. The vanishing of the sun: A manifestation of cortical plasticity. Surv Ophthalmol 1998;42:449-51.

25 Ramachandran VS, Aiken GW. Perceptual fading of visual texture borders. Vision Res 1993:33:717-21.

26 Kowler $\mathbf{E}$. The stability of gaze and its implications for vision. In: Carpenter RHS, ed. Vision and visual dysfunction: 8. Eye movements. Houndmills: Macmillan press, scientific and medical, 1991:71-92.

27 Rattliff F, Riggs LA. Involuntary motion of the eye during monocular fixation. J Eur Psychol 1950;40:687-701.

28 Ditchburn RW, Ginsborg BL. Vision with a stabilised retinal image. Nature 1952; 170:36-7.

29 Riggs LA, Ratliff F, Cornsweet JC, et al. The disapearance of steadily fixated test objects. J Opt Soc Am 1953;43:495-501.

30 Ditchburn RW. The function of small saccades. Vision Res 1980;20:271-2.

31 Hammet ST, Snowden RJ, Smith AT. Perceived contrast as a function of adaptation duration. Vision Res 1994;34:31-40.

32 Ditchburn RW, Drysdale AE. The effect of retinal image movements on visionII. Oscillatory movements. Proc R Soc Lond B Biol Sci 1977; 197:385-406.

33 Kowler E. Small saccades serve no useful purpose: reply to a letter by RW Ditchburn. Vision Res 1980;20:273-6.

34 Whittaker SG, Cummings RW, Swieson LR. Saccade control without a fovea. Vision Res 1991;31:2209-18.

35 Duret F, Buquet C, Charlier J, et al. Refixation strategies in four patients with macular disorders. Neuro-Ophthalmol 1999;22:209-20.

36 Crossland MD, Rubin GS. The use of an infrared eytracker to measure fixation stability. Optom Vis Sci 2002;79:735-9. 